Review Article

\title{
Knowing Your Beans in Parkinson's Disease: A Critical Assessment of Current Knowledge about Different Beans and Their Compounds in the Treatment of Parkinson's Disease and in Animal Models
}

\author{
Michel Rijntjes (D) \\ Dept. of Neurology, Medical Center, University of Freiburg, Freiburg, Germany \\ Correspondence should be addressed to Michel Rijntjes; michel.rijntjes@uniklinik-freiburg.de \\ Received 6 June 2019; Revised 21 September 2019; Accepted 3 October 2019; Published 30 October 2019
}

Academic Editor: Hélio Teive

Copyright (c) 2019 Michel Rijntjes. This is an open access article distributed under the Creative Commons Attribution License, which permits unrestricted use, distribution, and reproduction in any medium, provided the original work is properly cited.

\begin{abstract}
This review contains a critical appraisal of current knowledge about the use of beans in both animal models and patients with Parkinson's disease (PD). The potential beneficial effects of beans in PD are increasingly being touted, not only in scientific journals but also by the lay media. While there is a long tradition in Ayurvedic medicine of prescribing extracts from Mucuna pruriens (MP), whose seeds contain 5\% L-3,4-dihydroxyphenylalanin (L-DOPA), many other beans also contain L-DOPA (broad beans, common beans, and soybeans) or have other ingredients (coffee and cocoa) that may benefit PD patients. Indeed, beanderived compounds can elicit neuroprotective effects in animal models of PD, while several studies in human PD patients have shown that motor performance can improve after ingestion of bean extracts. However, there are several arguments countering the view that beans serve as a natural therapy for PD: (i) the results from animal PD models are not necessarily directly applicable to humans; (ii) beans have many bioactive ingredients, some of which can be harmful in large doses; (iii) studies in human PD patients are scarce and only report on the effects of single doses or the administration of bean extract over short periods of time; and (iv) no data on long-term efficacy or side effects of bean therapy are available. Therefore, reservations about the use of beans as a "natural" therapy for PD seem to be justified.
\end{abstract}

\section{Introduction}

A physician taking care of a patient suffering from PD will eventually be asked whether it is advisable to take a preparation from the plant Mucuna pruriens (MP), whose seeds contain 5\% L-DOPA [1]. Ayurvedic medicine has a long tradition of treating PD with MP, and many patients, especially in western countries, prefer to take "natural" remedies instead of pharmaceuticals. Moreover, when physicians ask their PD patients directly, they may be surprised about the high number who reveal that they already have experience with this herbal medicine.

The term "bean" is traditionally used for any plant belonging to the family Fabaceae-to which Mucuna, broad beans, common beans, and soy belong-but over time has also come to include seeds from other plants such as coffee and cocoa [2]. Beans other than MP are repeatedly mentioned in scientific reports and patient forums as being potentially beneficial in $\mathrm{PD}$, due to the fact that they contain either L-DOPA (broad beans, common beans, and soy) or other compounds (coffee and cocoa). Therefore, some background information on the medical history of these types of beans results from animal models, and their use in PD might be helpful not only for advising PD patients, but also for assessing scientific reports and addressing the sometimes speculative claims by the media.

\section{Methods}

The primary database was PubMed. Search terms were the names of the six beans dealt with in this review (both their botanical and common names) in combination with either 
the term "parkinson" or "L-DOPA." For cacao beans, additional search combinations were the combination of "theobromine" combined with "parkinson." For coffee beans, the combination was "caffeine" and "parkinson." All original studies that were thus retrieved and dealt with human subjects (also case reports) till March 2019 were included. Animal experiments were included when compounds showed clinical improvement in neuroprotective properties or might shed light on biochemical processes. Some articles led to references in journals and books that are not listed in PubMed, like agricultural journals, but especially historical sources. In such cases, the original texts in journals, books, and publications from NGOs were searched for information about beans on their first use in human society, their geographical dissemination, their use in traditional medicine, the first chemical isolation, relevant biochemical properties, and knowledge about compounds isolated that might have an impact on neuroprotection and Parkinson's disease. References where the original text was not available for scrutiny were not included.

\subsection{Mucuna pruriens (Velvet Bean). Mucuna pruriens (MP)} is an annual plant originating from South-East Asia [3]. The term "pruriens" refers to the extreme itchiness that occurs after contact with the hairy pods, provoked by the toxin mucunain [4]. As far as it is known, MP contains the highest amount of L-DOPA [1], which plants deploy as a biological defense mechanism. Roots excrete L-DOPA in large amounts, in Mucuna plantations up to $400 \mathrm{~kg}$ L-DOPA per hectare per year [5]. L-DOPA is toxic to parasitic insects [6] such as nematodes, some of which infect plant roots. L-DOPA also inhibits the growth of neighboring plants-at a strength 100-fold higher than glyphosate [7]-likely interfering with amino acid synthesis and cell wall lignification [8]. L-DOPA is also toxic to herbivore insects; focal damage to Mucuna leaves, which already contain $1 \% \mathrm{~L}$-DOPA, leads to local upregulation of L-DOPA [9].

In rat [10-12] and macaque monkey $[13,14]$ models of PD, MP preparations induced improvements in motor skills and dyskinesia similar to those induced by equivalent doses of L-DOPA. Another study compared the effects of L-DOPA vs. MP extract using a Drosophila model of autosomal recessive $\mathrm{PD}$ in which flies carried a mutation in the PTEN-induced putative kinase 1 (PINK-1) gene. Drosophila that was fed MP had a significantly extended lifespan, showed a restored olfactory response, and improved climbing behavior compared to flies that consumed L-DOPA [15]. Interestingly, MP was also reported to have neuroprotective properties, with the rescue of both tyrosine hydroxylase expression and damaged mitochondria. Additional animal studies have shown that MP exerts protective effects on neuronal cells under different neurotoxic conditions [16-18].

Mucuna seeds are rich in protein and in their processed form serve as a food supplement in several regions in Africa and Asia [19]. Raw seeds are not considered safe for human consumption due to the high amount of toxic alkaloids such as L-DOPA, as well as the hallucinogen dimethyltryptamine [20]. The concentration of these components can only be reduced by roasting, drying, or cooking, whereby the cooking water needs to be discarded repeatedly [3, 19]. Accordingly, during the 1989 civil war in Mozambique, mass psychosis was reported in a remote area in which the inhabitants were forced to nourish themselves with Mucuna beans, but had insufficient amounts of water to boil them in [20]. Their nonnutritious contents also limit the use of untreated Mucuna seeds as animal feed, except for ruminating mammals, who can adapt to L-DOPA via a microbialdriven fermentation process [3].

Ayurveda (Sanskrit: "Knowledge of life") is the traditional form of medicine practiced in India. It assumes three kinds of energy ("dosha") in the human body [21]: kapha, pitta, and vata, which are balanced in a healthy person. Vata (associated with the element of air) is the energy of movement, and too little or too much vata leads to diseases associated with the nervous system. The first description of PD symptoms in Ayurvedic literature possibly appeared around 600 BCE [22]. The Sanskrit word for tremor is "kampa," and in $300 \mathrm{CE}$, the Indian physician Charaka used the term "Kampavata" to describe a syndrome characterized by bradykinesia, tremor, gait disorder, depression, and dementia [21]. Charaka recommended Mucuna (Sanskrit: "Atmagupta") for the treatment of Kampavata.

The content of L-DOPA in dried and roasted Mucuna seeds varies between 4 and 6\% (seeds from closer to the equator have a higher L-DOPA concentration [23]), while boiling reduces the content to about 1.5\% [24]. Ayurvedic scripture suggests dissolving them in cow's milk [22]. The L-DOPA concentration of MP preparations depends on the method of extraction (e.g., with alcohol or water) [23, 25], and the dosage of L-DOPA in commercially available capsules varies widely between 60 and $500 \mathrm{mg}$.

Several studies have investigated the effect of MP in PD patients. Mucuna does not contain a DOPA decarboxylase inhibitor (DDCI), and without DDCI, the bioavailability of L-DOPA in the central nervous system is about one-fifth when combined with carbidopa or benserazide [26, 27]. Nonetheless, after a first report in 1978 on 23 PD patients who were treated with MP with similar effect and better tolerance than L-DOPA/benserazide [28], an open study in $60 \mathrm{PD}$ patients in Hoehn and Yahr stage I-IV (about half of them were L-DOPA naïve) showed that treatment with MP preparations over 12 weeks led to significant improvements in both UPDRS score and the Hoehn and Yahr stage [29], which led to the registration of a Mucuna preparation $\left(\right.$ Zandopa $\left.^{\mathrm{TM}}\right)$ as a treatment for PD in India.

When tested in small groups of PD patients in an advanced stage with motor fluctuations and peak-of-dose dyskinesias, a single dose of MP powder led to improvements in UPDRS, similar to the effects elicited by an equivalent dose of synthetic L-DOPA/DDCI and a longer "on" time $[30,31]$. Interestingly, in one of these investigations, the pharmacokinetic profile of plasma L-DOPA concentration suggested that Mucuna formulations have a higher bioavailability than a standard L-DOPA preparation combined with DDCI [30].

In a crossover study $(N=14)$, PD patients in an advanced stage with motor fluctuations and peak-of-dose dyskinesias 
receiving a powder extract of Mucuna dissolved in water showed similar motor improvement compared to an equivalent dose of L-DOPA/benserazide, but half of the patients had to discontinue MP prematurely because of nausea $(N=3)$ or worsening motor performance $(N=4)$. This worsening was probably due to the reduced number of doses of L-DOPA per day with reoccurrence of wearing-off. However, those who discontinued because of nausea reported a better tolerability of ingesting the supernatant component from a solution of MP powder and water, without a change in MP-induced efficacy [32].

2.2. Vicia faba (Broad Bean). Vicia faba beans were first cultivated in Mesopotamia [33] and then became widespread across the world, mainly because they also grow well in frosty areas such as northern Europe. Furthermore, dried fava beans have better storage properties than grains, making them suitable for use during winter [34]. In medieval Europe, fava beans and, to a lesser extent, peas and lentils represented the most important sources of protein since meat was expensive and its consumption was not permitted for religious reasons during the approximately 200 so-called "lean days" of the year [35].

Fava beans contain $0.5 \%$ L-DOPA $(0.07 \%$ when dried) [1]. It was Vicia faba from which L-DOPA was first isolated by Guggenheim in 1913, while the discovery of the enzyme DOPA decarboxylase by Holtz in 1938 revealed that L-DOPA is the precursor of dopamine [36].

Although Vicia faba preparations have not been tested in animal models of PD, there do exist several anecdotal reports on their effects in humans. Apaydin and colleagues described 3 PD patients (Hoehn and Yahr stage II) who had "on-off" fluctuations and were given $250 \mathrm{~g}$ of cooked fava beans twice a day [37]. After one week of treatment, the authors observed prolonged "on" periods with reduced dyskinesia and markedly reduced time in the "off" period, while one patient was able to substantially reduce his L-DOPA medication. Apaydin et al. also reported that patients who tried dried beans did not experience any clinical benefits. Another case report describes an otherwise healthy 73-year-old PD patient in Hoehn and Yahr stage III who was on $800 \mathrm{mg}$ L-DOPA/carbidopa per day and only had slight fluctuations. Two hours after eating a copious portion of freshly harvested raw fava beans, the patient experienced sudden agitation, severe chorea, tachycardia, anxiety, and vomiting, with full recovery 48 hours later [38]. Two small studies with $6 \mathrm{PD}$ patients each compared the effects of a fava bean serving (cooked or microwaved) versus the equivalent dose of L-DOPA/carbidopa and reported that both the beans and the pharmaceuticals led to an improvement in the Webster score and caused dyskinesia to a similar extent $[39,40]$.

2.3. Phaseolus vulgaris (Common Bean and Green Bean). Genetic studies of Phaseolus vulgaris suggest that this bean originated in Mesoamerica and later became domesticated in the Andes [41]. However, because the Andean variety thrives well in colder climates, it became the most popular strain in Europe [42]. The Arawak Indians who cultivated Phaseolus beans were spread throughout the Amazon basin from the Andean zone to the Caribbean [43] and were the first indigenous people that Columbus encountered in 1492. Upon returning from his first voyage, Columbus took some of the native people (most probably by force), birds, and plants back with him to show the King and Queen of Spain. Among the plants were Phaseolus beans, and he noted in his diary that they were "...fabas muy diversas de los nuestras. .." [44]. From that point onwards, they became the most important food legume in the world for direct consumption [3]. According to the Food and Agriculture Organization of the United Nations (FAO), green beans are practically the "perfect food" because they are so rich in nutrients, acting as a source of protein, vitamins, minerals, fiber, complex carbohydrates, and iron [45].

Phaseolus vulgaris contains $0.25 \%$ L-DOPA [1]. One study in which rats were induced into a cataleptic state by chlorpromazine or haloperidol reported that treatment with a methanol extract of Phaseolus beans led to an improvement on a cataleptic score [46]. Despite the absence of reports on the use of Phaseolus in human PD patients, Phaseolus is being viewed as a potential therapeutic means in $\mathrm{PD}$, and research efforts are being directed towards identifying the best cultivating conditions under which the amount of L-DOPA in Phaseolus can be increased [47].

2.4. Glycine max (Soybean). Soybeans are native to East Asia and contain $0.02 \%$ L-DOPA [1]. Like Vicia faba and Phaseolus, they are rich in protein, vitamins, minerals, and fiber. The earliest mention of its domestication stems from China, and according to Chinese mythology, at around 2800 BCE, Emperor Shennong taught his people about the practice of agriculture and the use of herbal medicines, proclaiming that soy was one of five sacred plants [48].

Like in India, PD was probably already known in ancient China. In the Chinese medical classic the "Yellow Emperor's Internal Classic Plain Questions," written in the $5^{\text {th }}$ century $\mathrm{BCE}$, the following description of a disease is given: "A person appears with crouching of the head and with staring eyes, bending the trunk with shoulders drooped, with difficulty turning and rocking the low back, inability of the knees to flex and extend, with the back bowed, failure to stand for long periods, and tremor while walking" (cited from [49]).

In traditional Chinese medicine (TCM), diseases are caused by five different outside influences, namely (associated element): wind (wood), cold (water), heat (fire), dampness (earth), and dryness (metal) [50], and tremor and stiffness are thought to result from the influence of wind [49]. Since 300 BCE, soybeans have been used as herbal medicine for diarrhea and coughing [51], while several other herbs and plants are recommended for alleviating the symptoms of tremor and stiffness [49]. However, there is no evidence to suggest that soybeans were ever used as a therapy for a disease resembling PD.

There are a few reports on the neuroprotective effect of soybeans in animal models, one of them in toxin-induced 
parkinsonism [52]. A crossover design study in humans compared the effect of a single dose of $100 \mathrm{mg}$ L-DOPA/ $25 \mathrm{mg}$ carbidopa in 7 Parkinson patients, with or without the addition of $11 \mathrm{~g}$ of soybeans (from Hokkaido, roasted for $15 \mathrm{~min}$ at $150^{\circ} \mathrm{C}$ and then pulverized) [53]. After 3 hours, MDS-UPDRS III did not differ between treatment groups, but the addition of soybeans led to significantly less dyskinesias on the modified abnormal involuntary movement score (mAIMS) and a longer mean "on" period of $75 \mathrm{~min}$, the latter assessed using a self-rating scale. The higher 3-Omethyldopa (3-OMD) and lower homovanillic acid (HVA) serum levels following supplementation with soybeans could be explained by an inhibitory effect on catechol-O-methyltransferase (COMT), suggesting that soybeans contain additional components that increase the bioavailability of L-DOPA. Soybean is a source of genistein [54], which was shown to inhibit peripheral DOPA decarboxylase activity [55]. This activity may influence the bioavailability of levodopa, though the daily amount needed to achieve an effective concentration is not known.

2.5. Coffea (Coffee Bean). The coffee plant originates in Ethiopia, where coffee beans mixed with fat were traditionally used by wandering tribes for sustenance [56]. Coffee beans were known to the Persian physician Avicenna around the year 1000, who pointed out its invigorating properties, but for reasons unknown, it was only from the $16^{\text {th }}$ century onwards that brewed coffee became a worldwide popular drink, thanks to Arab traders [56]. Caffeine is part of the defense mechanism of the coffee plant, being toxic to herbivore insects. It was first isolated by the chemist Runge in 1819, after Goethe encouraged him to find the active ingredient of coffee beans [57].

Many studies have shown a dose-related inverse relationship between coffee consumption and the risk of developing PD (e.g., [58, 59]). This association is usually attributed to the effect of caffeine: serum levels of caffeine are reduced in patients in early stage PD compared to agematched controls, irrespective of their actual coffee consumption [60]. Based on the results of animal model experiments, the proposed mechanisms underlying the neuroprotective and anti-inflammatory effects of caffeine include the following: (i) acting as an antagonist of the adenosine receptor A2a [61, 62]; (ii) increasing the plasma levels of the neurotrophic factor G-CSF [63]; and (iii) directly interfering with a-synuclein folding [64]. The dietary fiber derived from coffee beans has been reported to increase the amount of fecal Prevotella bacteria [65], of which a low concentration in the human microbiome has been linked to PD $[65,66]$.

An open study in PD patients showed that ingestion of $200 \mathrm{mg}$ caffeine daily (equivalent to two cups of coffee) could improve the UPDRS score by an average of 5 points [67]. However, chronic coffee intake during the early stages of $\mathrm{PD}$ does not correlate with radionuclide uptake in DAT-SPECT [68], while in a double-blind, placebo-controlled, randomized study over 1.5 years, a daily intake of $200 \mathrm{mg}$ caffeine had no effect on a cohort of 60 PD patients [69].
One explanation for these apparently contradictive observations is the possibility that the correlation between the PD risk and coffee consumption (as well as smoking) might be subject to the "chicken or the egg" conundrum: because a parkinsonian personality is characterized by low sensation-seeking traits, people who are at risk of developing PD have less tendency to use stimulating substances such as caffeine (or nicotine) [70].

2.6. Theobroma cacao (Cocoa Bean). The cacao tree is native to South America and was widely cultivated before the arrival of the conquistadores. For the Aztecs, cocoa beans imported from the more southern Maya regions were considered a luxury. They were used as currency, and at the court of Montezuma, a drink ("chocolatl") was prepared from roasted cocoa beans mixed with vanilla and chili [71]. Cocoa beans were named Theobroma ("food of the gods") by Linnaeus. Its primary alkaloid with a concentration of $1 \%$ is the xanthine theobromine, which was first isolated from cocoa by the chemist Woskresensky in 1842 [72] and has a mildly stimulating effect on humans. Most animals metabolize theobromine at a much slower rate to humans, and even small quantities $(1 \mathrm{~g} / \mathrm{kg})$ of dark chocolate are poisonous to dogs, inducing vomiting, increased urine output, progressing to epileptic seizures, and arrhythmia [73].

Parkinson patients have an increased chocolate consumption rate compared to healthy controls [74]. Several components of cocoa that cross the blood-brain barrier and may improve mood have been implicated, especially xanthines such as theobromine and caffeine, as well as phenylethylamine. Phenylethylamine is not only a precursor of dopamine, but it also stimulates the release of norepinephrine and dopamine into the synaptic cleft [75], leading to a feeling of well-being. Theobromine is an adenosine receptor antagonist like caffeine and appears to have additional properties, such as reducing cellular oxidative stress and regulating gene expression [76]. Also, it induces the expression of brain-derived neurotrophic factor, which is associated with improved motor learning in a mouse model of PD [77].

In healthy human subjects, dark chocolate improves mood and general cognitive function whereas white chocolate (devoid of cocoa) does not [78]. However, when the effect of theobromine is directly compared to that of caffeine in healthy subjects, the positive effect on mood appears mainly attributable to caffeine $[79,80]$, even when taking into consideration the fact that the liver metabolizes caffeine to $12 \%$ theobromine in humans [81]. Furthermore, in a crossover design study of moderately affected PD patients, a single $200 \mathrm{mg}$ dose of dark chocolate with $80 \%$ cocoa did not differ from $200 \mathrm{mg}$ of white chocolate in terms of its effects on the UPDRS motor score, Global Clinical Impression Score, or Beck's Depression Inventory [82].

Clovamide ( $N$-caffeoyl-L-DOPA), a conjugate of L-DOPA, was first isolated from red clover (Trifolium pratense) [83], which belongs to the bean family (Fabaceae), and later extracted from cocoa beans [84]. There are no reports of clovamide itself having a dopaminergic action, nor 
that it can be metabolized into its components in humans. Clovamide has neuroprotective properties in in vitro models of oxidative stress, excitotoxicity damage, and ischemia/reperfusion [85]. Several analogues of clovamide are now being investigated, both for their effectiveness against oxidative stress [86] and for their anti-inflammatory properties [87], with the aim of leading to a neuroprotective treatment in PD.

\section{Critical Appraisal and Conclusion}

The types of beans described in this overview all appear to have neuroprotective properties in animal models of PD, some of them being associated with improved motor performance. These effects are seen after the administration of either a bean extract or an individual compound. However, some important facts need to be kept in mind regarding animal models of PD. Firstly, the neuroprotective effects of individual compounds in animals are sometimes only observed in doses that would be toxic to humans [61]. Secondly, animal models usually focus on basal ganglia pathology and motor performance, whereas in humans, deposits of a-synuclein-the signature protein of $\mathrm{PD}$-are found in many other parts of the central and peripheral nervous system, often long before the characteristic motor symptoms become apparent [88]. Thirdly, animals do not suffer from PD in the wild. Animal models of PD are based on genetic mutations or toxin-induced parkinsonism, and therefore, the findings are not necessarily applicable to a slow-progressing neurodegenerative disease in humans.

Extracts from most beans containing L-DOPA can improve motor symptoms in PD patients, sometimes with reduced dyskinesia. However, most studies only report the results after administration of a single dose of extracts in small groups of patients, or as case reports, and data on bean extracts given over periods longer than a few months are not available. An international, multicenter RCT on the noninferiority of Mucuna powder versus commercial levodopa/ benserazide 200/50 mg tablets for long-term efficacy and safety is currently ongoing in newly diagnosed PD patients in the early stage of disease (Pan African Clinical Trials Registry, number 201611001882367).

It has to be taken into account that all beans have many ingredients that may be biologically active. For example, although cohort studies show that moderate consumption of coffee (3-5 cups per day) is associated with the decreased risk for developing several chronic ailments such as cerebrovascular disease [89], diabetes [90], and dementia [91], the effects of coffee and other beans might not be due to one ingredient alone (e.g., caffeine and L-DOPA), but rather to the synergistic actions between any other of the hundreds of different endogenous compounds (e.g., [15, 92]).

Individual compounds can also have side effects. While some are merely inconvenient, like the flatulence after Phaseolus consumption caused by fermentation of galactooligosaccharides [93], others can be harmful. The psychotropic effects of alkaloids in Mucuna pruriens were mentioned before, and consumption of a few raw kidney beans, a variety of Phaseolus vulgaris, leads to vomiting and diarrhea, due to the toxin phytohaemagglutinin [94]. The most consequential example is favism in individuals with glucose-6-phosphate dehydrogenase (G6PD) deficiency, which affects about 400 million people worldwide [95]. Vicia faba contains considerable amounts ( $2 \%$ of dry weight) of the $\beta$-glucosides vicine and convicine, whose metabolites produce highly reactive oxygen species that cannot be detoxified within G6PD-deficient red blood cells, leading to hemolysis [96].

In addition to $\mathrm{PD}$, Ayurvedic medicine recommends $\mathrm{MP}$ for many other affections such as snakebites, worm infections, diabetes, epilepsy, psoriasis, and depression, and as an aphrodisiac [97]. These last two indications could be attributed to the high concentration of L-DOPA. However, Mucuna seeds also contain many other compounds [3, 25], among them the degradation products of L-DOPA, which include quinones, other oxygen radicals, and several more reactive oxygen species [98]. Quinones might be the reason for the antimicrobial and antiparasitic use of MP in traditional medicine, but like oxygen radicals and other reactive oxygen species, they might play a role themselves in the development of PD [99].

MP was suggested as an alternative source of levodopa for PD patients who cannot afford therapy with commercial levodopa preparations [31]. However, because the long-term effects of the other compounds are unknown (with many of them not even being identified yet), others suggest a large amount of restraint [98]. Moreover, levodopa-induced dyskinesias develop in up to $80 \%$ of PD patients, depending on dosage and duration [100]. Regular ingestion of MP could accelerate the incidence of dyskinesia, and long-term data on MP in PD are completely lacking. Therefore, any study on the effects and tolerability of Mucuna in PD should be accompanied by measurements of plasma concentrations for an accurate calculation of L-DOPA intake.

Still, in low-income countries in which access to pharmaceutical L-DOPA preparations is severely limited, Mucuna might offer a potential alternative source of L-DOPA. In these cases, the intake of Mucuna preparations should be under supervision of physicians trained on its potential side effects and how to adjust the daily dosage, especially since the dosage in commercially available Mucuna capsules has a very wide range. However, patients taking MP preparations should be advised against concomitant intake of pharmaceutical preparations of L-DOPA, since the presence of the decarboxylase inhibitor might potentiate side effects.

In conclusion, until more information is available, reservations about the use of beans as a "natural" therapy for PD seem to be justified for the time being.

\section{Conflicts of Interest}

The author declares that there are no conflicts of interest regarding the publication of this paper.

\section{Acknowledgments}

I am grateful to Sandra Dieni for proofreading the manuscript. 


\section{References}

[1] K. B. Ramya and S. Thaakur, "Herbs containing L- Dopa: an update," Ancient Science of Life, vol. 27, no. 1, pp. 50-55, 2007.

[2] Editors of the American Heritage Dictionaries, American Heritage Dictionary of the English Language, Houghton Mifflin Harcourt, Boston, MA, USA, 2016.

[3] P. L. Sherasia, M. R. Garg, and B. M. Bhanderi, Pulses and Their By-Products as Animal Feed, Food and Agriculture Organization of the United Nations, Rome, Italy, 2017.

[4] W. B. Shelley and R. P. Arthur, "Mucunain, the active pruritogenic proteinase of cowhage," Science, vol. 122, no. 3167 , pp. 469-470, 1955.

[5] A. R. Soares, R. Marchiosi, C. Siqueira-Soares Rde, R. Barbosa de Lima, W. Dantas dos Santos, and O. FerrareseFilho, "The role of L-DOPA in plants," Plant Signaling \& Behavior, vol. 9, no. 4, Article ID e28275, 2014.

[6] S. S. Rehr, D. H. Janzen, and P. P. Feeny, "L-dopa in legume seeds: a chemical barrier to insect attack," Science, vol. 181, no. 4094, pp. 81-82, 1973.

[7] M. L. Martin and A. E. Ronco, "Effect of mixtures of pesticides used in the direct seeding technique on nontarget plant seeds," Bulletin of Environmental Contamination and Toxicology, vol. 77, no. 2, pp. 228-236, 2006.

[8] G. S. Bido, H. A. D. Silva, T. Bortolo et al., "Comparative effects of L-DOPA and velvet bean seed extract on soybean lignification," Plant Signaling \& Behavior, vol. 13, no. 4, Article ID e1451705, 2018.

[9] M. Gish, M. C. Mescher, and C. M. De Moraes, "Targeted predation of extrafloral nectaries by insects despite localized chemical defences," Proceedings of the Royal Society B: Biological Sciences, vol. 282, no. 1816, Article ID 20151835, 2015.

[10] G. Hussian and B. V. Manyam, "Mucuna pruriens proves more effective thanl-DOPA in Parkinson's disease animal model," Phytotherapy Research, vol. 11, no. 6, pp. 419-423, 1997.

[11] S. Kasture, S. Pontis, A. Pinna et al., "Assessment of symptomatic and neuroprotective efficacy of Mucuna pruriens seed extract in rodent model of Parkinson's disease," Neurotoxicity Research, vol. 15, no. 2, pp. 111-122, 2009.

[12] C. A. Lieu, A. R. Kunselman, B. V. Manyam, K. Venkiteswaran, and T. Subramanian, "A water extract of Mucuna pruriens provides long-term amelioration of parkinsonism with reduced risk for dyskinesias," Parkinsonism \& Related Disorders, vol. 16, no. 7, pp. 458-465, 2010.

[13] C. A. Lieu, M. Deogaonkar, R. A. E. Bakay, and T. Subramanian, "Dyskinesias do not develop after chronic intermittent levodopa therapy in clinically hemiparkinsonian rhesus monkeys," Parkinsonism \& Related Disorders, vol. 17, no. 1, pp. 34-39, 2011.

[14] C. A. Lieu, K. Venkiteswaran, T. P. Gilmour et al., "The antiparkinsonian and antidyskinetic mechanisms of Mucuna pruriens in the MPTP-treated nonhuman primate, evidencebased complementary and alternative medicine," EvidenceBased Complementary and Alternative Medicine, vol. 2012, Article ID 840247, 2012.

[15] S. Poddighe, F. De Rose, R. Marotta et al., "Mucuna pruriens (velvet bean) rescues motor, olfactory, mitochondrial and synaptic impairment in PINK1B9 Drosophila melanogaster genetic model of Parkinson's disease," PLoS One, vol. 9, no. 10, Article ID e110802, 2014.

[16] S. K. Yadav, J. Prakash, S. Chouhan et al., "Comparison of the neuroprotective potential of Mucuna pruriens seed extract with estrogen in 1-methyl-4-phenyl-1,2,3,6-tetrahydropyridine (MPTP)-induced PD mice model," Neurochemistry International, vol. 65, pp. 1-13, 2014.

[17] S. N. Rai, H. Birla, W. Zahra, S. S. Singh, and S. P. Singh, "Immunomodulation of Parkinson's disease using Mucuna pruriens (Mp)," Journal of Chemical Neuroanatomy, vol. 85, pp. 27-35, 2017.

[18] S. L. Johnson, H. Y. Park, N. A. DaSilva, D. A. Vattem, H. Ma, and N. P. Seeram, "Levodopa-reduced Mucuna pruriens seed extract shows neuroprotective effects against Parkinson's disease in murine microglia and human neuroblastoma cells, Caenorhabditis elegans, and Drosophila melanogaster," $\mathrm{Nu}$ trients, vol. 10, no. 9, p. 1139, 2018.

[19] K. R. Sridhar and R. Bhat, "Agrobotanical, nutritional and bioactive potential of unconventional legume-Mucuna," Livestock Research for Rural Development, vol. 19, no. 9, 2007, http://www.lrrd.org/lrrd19/9/srid19126.htm.

[20] M. Infante, A. Perez, M. Simao et al., "Outbreak of acute toxic psychosis attributed to Mucuna pruriens," The Lancet, vol. 336, no. 8723, p. 1129, 1990.

[21] B. V. Manyam, "Paralysis agitans and levodopa in "Ayurveda": ancient Indian medical treatise," Movement Disorders, vol. 5, no. 1, pp. 47-48, 1990.

[22] S. Ovallath and P. Deepa, "The history of parkinsonism: descriptions in ancient Indian medical literature," Movement Disorders, vol. 28, no. 5, pp. 566-568, 2013.

[23] V. Vadivel and H. K. Biesalski, "Effect of certain indigenous processing methods on the bioactive compounds of ten different wild type legume grains," Journal of Food Science and Technology, vol. 49, no. 6, pp. 673-684, 2012.

[24] E. Cassani, R. Cilia, J. Laguna et al., "Mucuna pruriens for Parkinson's disease: low-cost preparation method, laboratory measures and pharmacokinetics profile," Journal of the Neurological Sciences, vol. 365, pp. 175-180, 2016.

[25] L. Misra and H. Wagner, "Extraction of bioactive principles from Mucuna pruriens seeds," Indian Journal of Biochemistry \& Biophysics, vol. 44, pp. 56-60, 2007.

[26] H. Mars, "Modification of levodopa effect by systemic decarboxylase inhibition," Archives of Neurology, vol. 28, no. 2, pp. 91-95, 1973.

[27] C. D. Marsden, J. D. Parkes, and J. E. Rees, “A year's comparison of treatment of patients with Parkinson's disease with levodopa combined with carbidopa versus treatment with levodopa alone," The Lancet, vol. 302, no. 7844, pp. 1459-1462, 1973.

[28] A. B. Vaidya, T. G. Rajagopalan, N. A. Mankodi et al., "Treatment of Parkinson's disease with the cowhage plantMucuna pruriens Bak," Neurology India, vol. 26, no. 4, pp. 171-176, 1978.

[29] B. V. Manyam, "An alternative medicine treatment for Parkinson's disease: results of a multicenter clinical trial," The Journal of Alternative and Complementary Medicine, vol. 1, no. 3, pp. 249-255, 1995.

[30] R. Katzenschlager, A. Evans, A. Manson et al., "Mucuna pruriens in Parkinson's disease: a double blind clinical and pharmacological study," Journal of Neurology, Neurosurgery \& Psychiatry, vol. 75, no. 12, pp. 1672-1677, 2004.

[31] R. Cilia, J. Laguna, E. Cassani et al., "Mucuna pruriens in Parkinson disease,” Neurology, vol. 89, no. 5, pp. 432-438, 2017.

[32] R. Cilia, J. Laguna, E. Cassani et al., "Daily intake of Mucuna pruriens in advanced Parkinson's disease: a 16-week, noninferiority, randomized, crossover, pilot study," Parkinsonism \& Related Disorders, vol. 49, pp. 60-66, 2018. 
[33] K. Albala, Beans, a History, Berg Publishers, New York, NY, USA, 2007.

[34] K. L. Pearson, "Nutrition and the early-medieval diet," Speculum, vol. 72, no. 1, pp. 1-32, 1997.

[35] M. W. Adamson, Food in Medieval Times, Greenwood Publishing Group, Santa Barbara, CA, USA, 2008.

[36] O. Hornykiewicz, "L-DOPA: from a biologically inactive amino acid to a successful therapeutic agent," Amino Acids, vol. 23, no. 1-3, pp. 65-70, 2002.

[37] H. 1. Apaydin, S. Ertan, and S. Özekmekçi, "Broad bean (Vicia faba)-A natural source of L-dopa-prolongs "on" periods in patients with Parkinson's disease who have "onoff” fluctuations," Movement Disorders, vol. 15, no. 1, pp. 164-166, 2000.

[38] J. M. Ramírez-Moreno, I. Salguero Bodes, O. Romaskevych, and M. C. Duran-Herrera, "Broad bean (Vicia faba) consumption and Parkinson's disease: a natural source of L-dopa to consider," Neurología, vol. 30, no. 6, pp. 375-376, 2015.

[39] J. M. Rabey, Y. Vered, H. Shabtai, E. Graff, and A. D. Korczyn, "Improvement of parkinsonian features correlate with high plasma levodopa values after broad bean (Vicia faba) consumption," Journal of Neurology, Neurosurgery \& Psychiatry, vol. 55, no. 8, pp. 725-727, 1992.

[40] P. A. Kempster, Z. Bogetic, J. W. Secombei, H. D. Martin, N. D. Balazs, and M. L. Wahlqvist, "Motor effects of broad beans (Vicia faba) in Parkinson's disease: single dose studies," Asia Pacific Journal of Clinical Nutrition, vol. 2, no. 2, pp. 85-89, 1993.

[41] E. Bitocchi, L. Nanni, E. Bellucci et al., "Mesoamerican origin of the common bean (Phaseolus vulgaris L.) is revealed by sequence data," Proceedings of the National Academy of Sciences, vol. 109, no. 14, pp. E788-E796, 2012.

[42] E. Belluci, E. Bitocchi, D. Rau et al., "Genomics of Origin, domestication and evolution of Phaseolus vulgaris," in Genomics of Plant Genetic Resources, R. Tuberosa, A. Graner, and E. Frison, Eds., pp. 483-507, Springer, Dordercht, Netherlands, 2013.

[43] H. Schroeder, M. Sikora, S. Gopalakrishnan et al., "Origins and genetic legacies of the caribbean taino," Proceedings of the National Academy of Sciences, vol. 115, no. 10, pp. 2341-2346, 2018.

[44] C. ColonDiario de a bordo Editorial Edaf, Madrid, 2006.

[45] A. L. Jones, Phaseolus Bean: Post-Harvest Operations, Food and Agriculture Organization of the United Nations, Rome, Italy, 1999.

[46] R. Anandpara, B. Sojitra, Y. Nakhva, and T. Ganatra, "Evaluation and comparison of anti-Parkinson activity of methanolic extract of Phaseolus vulgaris with L-DOPA," International Journal of Pharmacological Research, vol. 5, no. 2, pp. 103-108, 2015.

[47] C. A. Oviedo-Silva, M. Elso-Freudenberg, and M. ArandaBustos, "L-DOPA trends in different tissues at early stages of Vicia faba growth: effect of tyrosine treatment," Innovative Food Science \& Emerging Technologies, vol. 5, no. 2, pp. 235-244, 2004.

[48] A. Christie, Chinese Mythology, Hamlyn, London, UK, 1975.

[49] Z.-X. Zhang, Z.-H. Dong, and G. C. Román, "Early descriptions of Parkinson disease in ancient China," Archives of Neurology, vol. 63, no. 5, pp. 782-784, 2006.

[50] M. Dashtdar, M. R. Dashtdar, B. Dashtdar, K. Kardi, and M. k. Shirazi, "The concept of wind in traditional Chinese medicine," Journal of Pharmacopuncture, vol. 19, no. 4, pp. 293-302, 2016.
[51] D. Bensky, S. Clavey, and E. Stoeger, Chinese Herbal Medicine: Materia Medica, Eastland Press, Vista, CA, USA, 2015.

[52] Z. Guo, W. Cao, S. Zhao, Z. Han, and B. Han, "Protection against 1-methyl-4-phenyl pyridinium-induced neurotoxicity in human neuroblastoma SH-SY5Y cells by Soyasaponin I by the activation of the phosphoinositide 3-kinase/ AKT/GSK3 $\beta$ pathway," Neuroreport, vol. 27, no. 10, pp. 730-736, 2016.

[53] Y. Nagashima, T. Kondo, M. Sakata, J. Koh, and H. Ito, "Effects of soybean ingestion on pharmacokinetics of levodopa and motor symptoms of Parkinson's disease-in relation to the effects of Mucuna pruriens," Journal of the Neurological Sciences, vol. 361, pp. 229-234, 2016.

[54] V. Mukund, D. Mukund, V. Sharma, M. Mannarapu, and A. Alam, "Genistein: its role in metabolic diseases and cancer," Critical Reviews in Oncology/hematology, vol. 119, pp. 13-22, 2017.

[55] H. Umezawa, H. Tobe, N. Shibamoto et al., "Isolation of isoflavones inhibiting DOPA decarboxylase from fungi and streptomyces," The Journal of Antibiotics, vol. 28, no. 12, pp. 947-952, 1975.

[56] B. A. Weinberg, The World of Caffeine: The Science and Culture of the World's Most Popular Drug, Routledge, Abington-on-Thames, UK, 2002.

[57] F. F. Runge, Hauswirthschaftliche Briefe. Erstes und Drittes Dutzend, G. A. Koenig's Verlag, Berlin, Germany, 1865.

[58] G. W. Ross, R. D. Abbott, H. Petrovitch et al., "Association of coffee and caffeine intake with the risk of Parkinson disease," Jama, vol. 283, no. 20, pp. 2674-2679, 2000.

[59] H. Qi and S. Li, "Dose-response meta-analysis on coffee, tea and caffeine consumption with risk of Parkinson's disease," Geriatrics \& Gerontology International, vol. 14, no. 2, pp. 430-439, 2014.

[60] M. Fujimaki, S. Saiki, Y. Li et al., "Serum caffeine and metabolites are reliable biomarkers of early Parkinson disease," Neurology, vol. 90, no. 5, pp. e404-e411, 2018.

[61] M. Kolahdouzan and M. J. Hamadeh, "The neuroprotective effects of caffeine in neurodegenerative diseases," CNS Neuroscience \& Therapeutics, vol. 23, no. 4, pp. 272-290, 2017.

[62] M. Cieslak, M. Komoszynski, and A. Wojtczak, "Adenosine $\mathrm{A}(2 \mathrm{~A})$ receptors in Parkinson's disease treatment," Purinergic Signalling, vol. 4, no. 4, pp. 305-312, 2008.

[63] C. Cao, L. Wang, X. Lin et al., "Caffeine synergizes with another coffee component to increase plasma GCSF: linkage to cognitive benefits in Alzheimer's mice," Journal of Alzheimer's Disease, vol. 25, no. 2, pp. 323-335, 2011.

[64] O. Tavassoly, J. Kakish, S. Nokhrin, O. Dmitriev, and J. S. Lee, "The use of nanopore analysis for discovering drugs which bind to $\alpha$-synuclein for treatment of Parkinson's disease," European Journal of Medicinal Chemistry, vol. 88, pp. 42-54, 2014.

[65] N. Reichardt, D. Gniechwitz, H. Steinhart, M. Bunzel, and M. Blaut, "Characterization of high molecular weight coffee fractions and their fermentation by human intestinal microbiota," Molecular Nutrition \& Food Research, vol. 53, no. 2, pp. 287-299, 2009.

[66] F. Scheperjans, V. Aho, P. A. B. Pereira et al., "Gut microbiota are related to Parkinson's disease and clinical phenotype," Movement Disorders, vol. 30, no. 3, pp. 350-358, 2015.

[67] R. Liu, X. Guo, Y. Park et al., "Caffeine intake, smoking, and risk of Parkinson disease in men and women," American 
Journal of Epidemiology, vol. 175, no. 11, pp. 1200-1207, 2012.

[68] A. F. Gigante, A. N. Asabella, G. Iliceto et al., "Chronic coffee consumption and striatal DAT-SPECT findings in Parkinson's disease," Neurological Sciences, vol. 39, no. 3, pp. 551-555, 2018.

[69] R. B. Postuma, J. Anang, A. Pelletier et al., "Caffeine as symptomatic treatment for Parkinson disease (Café-PD)," Neurology, vol. 89, no. 17, pp. 1795-1803, 2017.

[70] A. H. Evans, A. D. Lawrence, J. Potts et al., "Relationship between impulsive sensation seeking traits, smoking, alcohol and caffeine intake, and Parkinson's disease," Journal of Neurology, Neurosurgery, and Psychiatry, vol. 77, no. 3, pp. 317-321, 2006.

[71] G. A. R. Wood and R. A. Lass, Cocoa, John Wiley \& Sons, Hoboken, NJ, USA, 2008.

[72] A. Woskresensky, "Ueber das Theobromin," Annalen der Chemie und Pharmacie, vol. 41, no. 1, pp. 125-127, 1842.

[73] S. B. Hooser and V. R. Beasley, Methylxanthine Poisoning (Chocolate and Caffeine Toxicosis), Current Veterinary Therapy for Small Animal Practice IX, Saunders, Philadelphia, PA, USA, 1986.

[74] M. Wolz, A. Kaminsky, M. Löhle, R. Koch, A. Storch, and H. Reichmann, "Chocolate consumption is increased in Parkinson's disease," Journal of Neurology, vol. 256, no. 3, pp. 488-492, 2009.

[75] G. M. Miller, "The emerging role of trace amine-associated receptor 1 in the functional regulation of monoamine transporters and dopaminergic activity," Journal of Neurochemistry, vol. 116, no. 2, pp. 164-176, 2011.

[76] E. Martinez-Pinilla, A. Onatibia-Astibia, and R. Franco, "The relevance of theobromine for the beneficial effects of cocoa consumption," Frontiers in Pharmacology, vol. 6, p. 30, 2015.

[77] M. Yoneda, N. Sugimoto, M. Katakura et al., "Theobromine up-regulates cerebral brain-derived neurotrophic factor and facilitates motor learning in mice," The Journal of Nutritional Biochemistry, vol. 39, pp. 110-116, 2017.

[78] H. J. Smit, E. A. Gaffan, and P. J. Rogers, "Methylxanthines are the psycho-pharmacologically active constituents of chocolate," Psychopharmacology, vol. 176, no. 3-4, pp. 412419, 2004.

[79] M. J. Baggott, E. Childs, A. B. Hart et al., "Psychopharmacology of theobromine in healthy volunteers," Psychopharmacology, vol. 228, no. 1, pp. 109-118, 2013.

[80] D. A. Judelson, A. G. Preston, D. L. Miller, C. X. Muñoz, M. D. Kellogg, and H. R. Lieberman, "Effects of theobromine and caffeine on mood and vigilance," Journal of Clinical Psychopharmacology, vol. 33, no. 4, pp. 499-506, 2013.

[81] M. E. Campbell, D. M. Grant, T. Inaba, and W. Kalow, "Biotransformation of caffeine, paraxanthine, theophylline, and theobromine by polycyclic aromatic hydrocarbon-inducible cytochrome(s) P-450 in human liver microsomes," Drug Metabolism and Disposition: The Biological Fate of Chemicals, vol. 15, no. 2, pp. 237-249, 1987.

[82] M. Wolz, C. Schleiffer, L. Klingelhöfer et al., "Comparison of chocolate to cacao-free white chocolate in Parkinson's disease: a single-dose, investigator-blinded, placebo-controlled, crossover trial," Journal of Neurology, vol. 259, no. 11, pp. 2447-2451, 2012.

[83] T. Yoshihara, H. Yoshikawa, S. Sakamura, and T. Sakuma, "Clovamides; 1-dopa conjugated with trans- and ciscaffeic acids in red clover (Trifolium pratense),"
Agricultural and Biological Chemistry, vol. 38, no. 5, pp. 1107-1109, 1974.

[84] C. Sanbongi, N. Osakabe, M. Natsume, T. Takizawa, S. Gomi, and T. Osawa, "Antioxidative polyphenols isolated from Theobromacacao," Journal of Agricultural and Food Chemistry, vol. 46, no. 2, pp. 454-457, 1998.

[85] S. Fallarini, G. Miglio, T. Paoletti et al., "Clovamide and rosmarinic acid induce neuroprotective effects inin vitromodels of neuronal death," British Journal of Pharmacology, vol. 157, no. 6, pp. 1072-1084, 2009.

[86] J.-H. Feng, X.-L. Hu, X.-Y. Lv et al., "Synthesis and biological evaluation of clovamide analogues with catechol functionality as potent Parkinson's disease agents in vitro and in vivo," Bioorganic \& Medicinal Chemistry Letters, vol. 29, no. 2, pp. 302-312, 2019.

[87] X.-L. Hu, J. Lin, X.-Y. Lv et al., "Synthesis and biological evaluation of clovamide analogues as potent anti-neuroinflammatory agents in vitro and in vivo," European Journal of Medicinal Chemistry, vol. 151, pp. 261-271, 2018.

[88] K. Doppler, H.-M. Jentschke, L. Schulmeyer et al., "Dermal phospho-alpha-synuclein deposits confirm REM sleep behaviour disorder as prodromal Parkinson's disease," Acta Neuropathologica, vol. 133, no. 4, pp. 535-545, 2017.

[89] G. Grosso, A. Micek, J. Godos et al., "Long-term coffee consumption is associated with decreased incidence of newonset hypertension: a dose-response meta-analysis," Nutrients, vol. 9, no. 8, 2017.

[90] P. Mirmiran, M. Carlström, Z. Bahadoran, and F. Azizi, "Long-term effects of coffee and caffeine intake on the risk of pre-diabetes and type 2 diabetes: findings from a population with low coffee consumption," Nutrition, Metabolism and Cardiovascular Diseases, vol. 28, no. 12, pp. 1261-1266, 2018.

[91] M. H. Eskelinen, T. Ngandu, J. Tuomilehto, H. Soininen, and M. Kivipelto, "Midlife coffee and tea drinking and the risk of late-life dementia: a population-based CAIDE study," Journal of Alzheimer's Disease, vol. 16, no. 1, pp. 85-91, 2009.

[92] B. Shukitt-Hale, M. G. Miller, Y.-F. Chu, B. J. Lyle, and J. A. Joseph, "Coffee, but not caffeine, has positive effects on cognition and psychomotor behavior in aging," Age, vol. 35, no. 6, pp. 2183-2192, 2013.

[93] M. Granito, M. Champ, A. David, C. Bonnet, and M. Guerra, "Identification of gas-producing components in different varieties of Phaseolus vulgaris byin vitro fermentation," Journal of the Science of Food and Agriculture, vol. 81, no. 6, pp. 543-550, 2001.

[94] FDA, Bad Bug Book, Handbook of Foodborne Pathogenic Microorganisms and Natural Toxins, Food and Drug Administration, Silver Spring, MD, USA, 2nd edition, 2012.

[95] E. T. Nkhoma, C. Poole, V. Vannappagari, S. A. Hall, and E. Beutler, "The global prevalence of glucose-6-phosphate dehydrogenase deficiency: a systematic review and metaanalysis," Blood Cells, Molecules, and Diseases, vol. 42, no. 3, pp. 267-278, 2009.

[96] L. Luzzatto and P. Arese, "Favism and glucose-6-phosphate dehydrogenase deficiency," The New England Journal of Medicine, vol. 378, no. 11, pp. 1068-1069, 2018.

[97] L. R. Lampariello, A. Cortelazzo, R. Guerranti, C. Sticozzi, and G. Valacchi, "The magic velvet bean of Mucuna pruriens," Journal of Traditional and Complementary Medicine, vol. 2, no. 4, pp. 331-339, 2012.

[98] H. Pulikkalpura, R. Kurup, P. J. Mathew, and S. Baby, "Levodopa in Mucuna pruriens and its degradation," Scientific Reports, vol. 5, p. 11078, 2015. 
[99] J. Segura-Aguilar, I. Paris, P. Muñoz, E. Ferrari, L. Zecca, and F. A. Zucca, "Protective and toxic roles of dopamine in Parkinson's disease," Journal of Neurochemistry, vol. 129, no. 6, pp. 898-915, 2014.

[100] V. Voon, T. C. Napier, M. J. Frank et al., "Impulse control disorders and levodopa-induced dyskinesias in Parkinson's disease: an update," The Lancet Neurology, vol. 16, no. 3, pp. 238-250, 2017. 


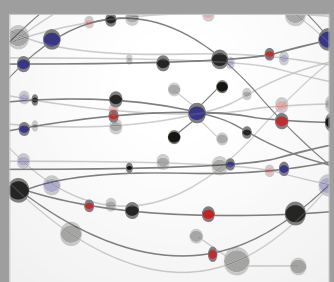

The Scientific World Journal
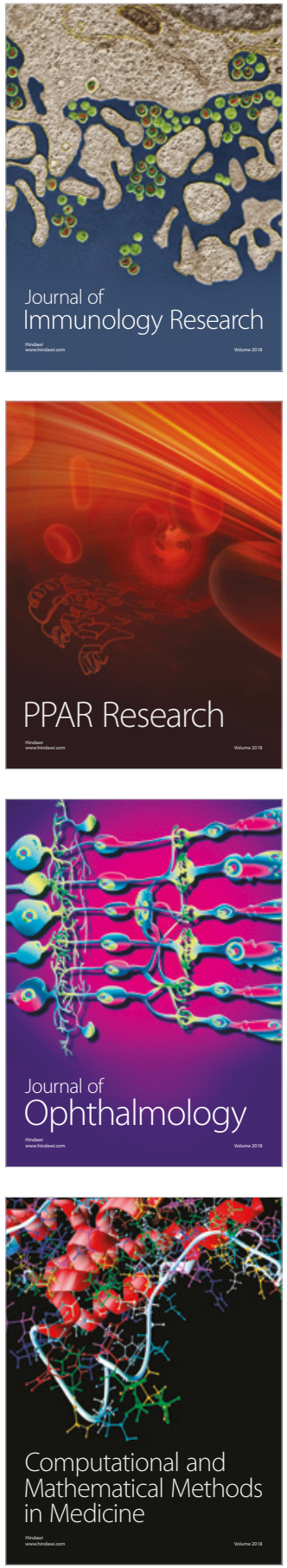

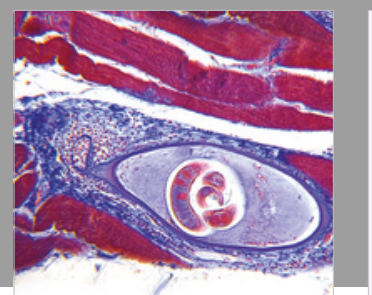

Gastroenterology Research and Practice

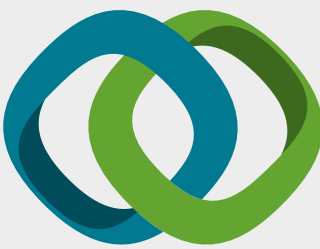

\section{Hindawi}

Submit your manuscripts at

www.hindawi.com
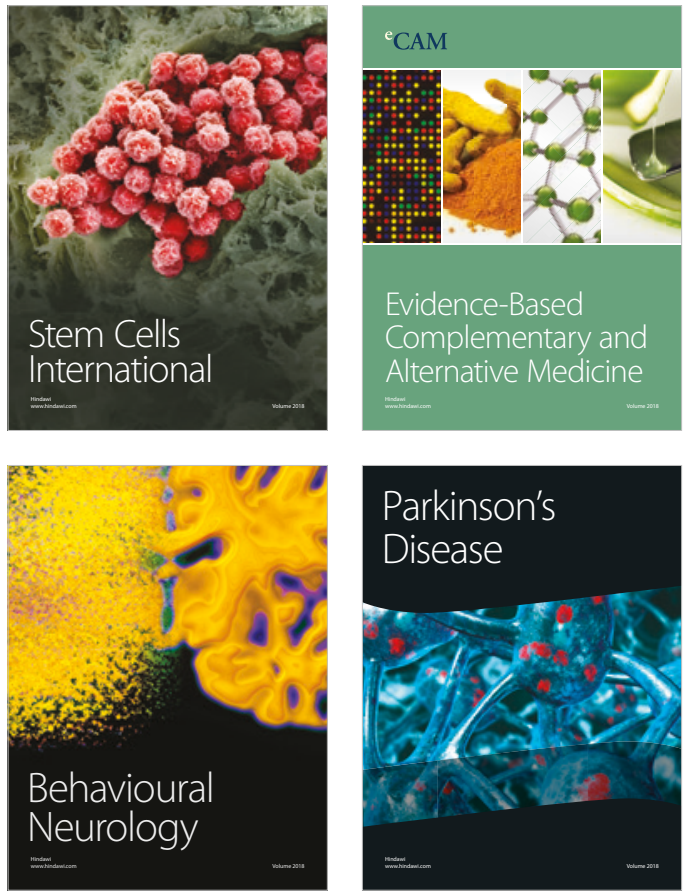

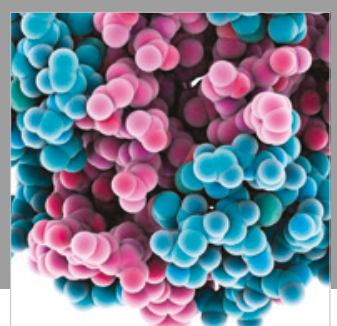

ournal of

Diabetes Research

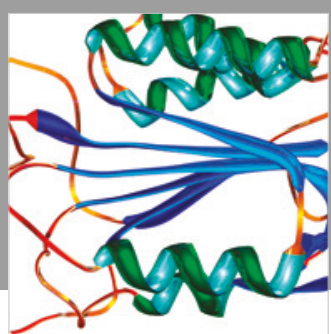

Disease Markers
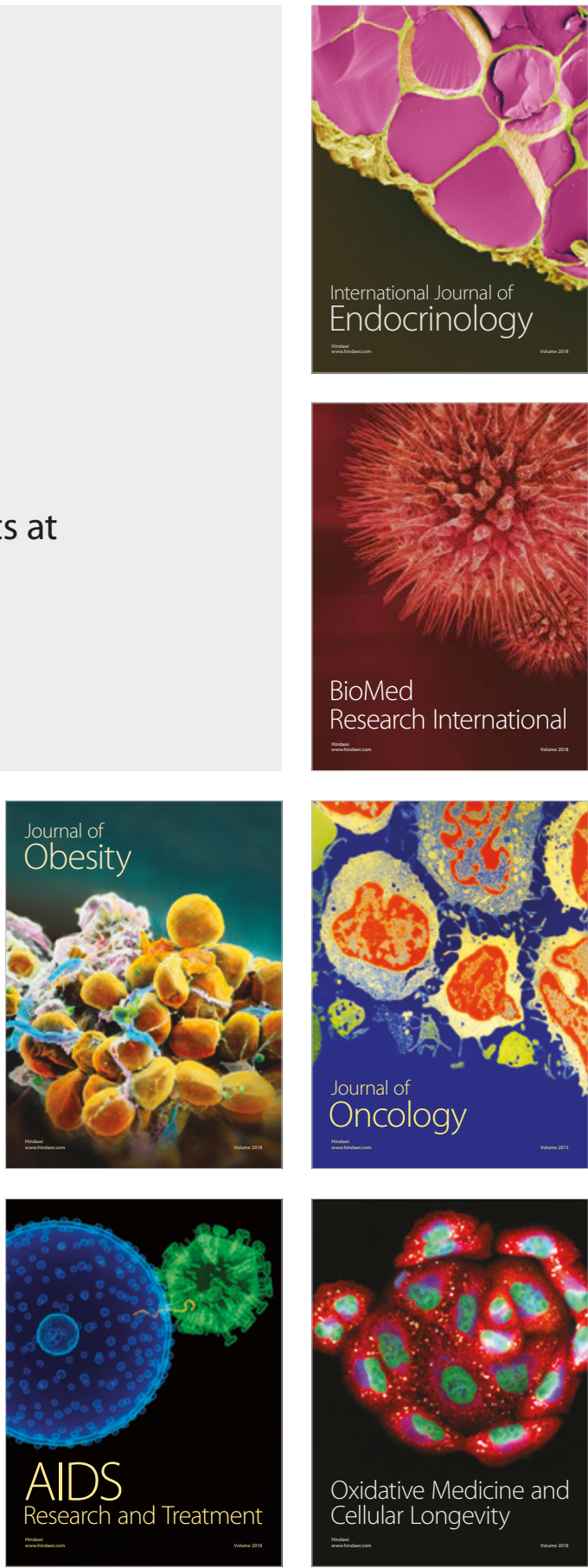